\title{
Injection-dependent lateral resistance in front-junction solar cells with nc-Si:H and a-Si:H hole selective contact
}

\author{
Jan Haschke ${ }^{1}$, Christoph Messmer ${ }^{2}$, Jean Cattin ${ }^{1}$, Martin Bivour ${ }^{2}$, Mathieu Boccard ${ }^{1}$, Christophe Ballif ${ }^{1}$ \\ ${ }^{1}$ Photovoltaics and Thin-Film Electronics Laboratory (PV-lab), Institute of Microengineering, Ecole Polytechnique Fédérale de \\ Lausanne, Rue de la Maladière 71B, CH-2002 Neuchâtel, Switzerland \\ ${ }^{2}$ Fraunhofer Institute for Solar Energy Systems (ISE), Heidenhofstrasse 2, D-79110 Freiburg, Germany
}

\begin{abstract}
We investigate the role of lateral transport of minority carriers in the wafer for front-junction solar cells. The study is based on two silicon heterojunction solar cells with p-type amorphous (a-Si), and nanocrystalline (nc-Si) silicon as hole selective layer respectively. The solar cells feature similar certified efficiencies $(23.23 \%$ and $23.45 \%)$. Unexpectedly, FF and $R_{S}$ at MPP of both solar cells are also similar. Fitting the JV curves in high-forward bias, and analytical calculations suggest that lateral transport is also taking place in the wafer at high injection, despite the front-junction configuration. This is supported by numerical device simulations. Both reveal that junction-related $R_{s}$ is lower with $\mathrm{nc}-\mathrm{Si}(\mathrm{p})$ than with $\mathrm{a}-\mathrm{Si}(\mathrm{p})$. The results underline the importance of analyzing JV curves over a wide voltage range to unravel different phenomena determining FF.
\end{abstract}

Index Terms - amorphous materials, crystalline materials, fillfactor, loss analysis, numerical simulation, photovoltaic cells, silicon.

\section{INTRODUCTION}

Silicon heterojunction (SHJ) solar cells offer the highest efficiency among silicon based solar cells to date [1], [2]. For two-side contacted SHJ solar cells, a transparent conductive oxide TCO, usually ITO, is needed for lateral current transport at the front-side. The properties of ITO can depend on the layer it is deposited onto [3], with one key factor being hydrogen. Generally, nanocrystalline p-type silicon (nc-Si(p)) is considered to facilitate contact formation to ITO and thus leading to higher FF when used as hole contact layer over amorphous p-type silicon (a-Si(p)) [4], [5].

In this work, we calculate the contribution to lateral conduction from the wafer for two SHJ solar cells featuring $n c-\operatorname{Si}(\mathrm{p})$ and a-Si(p) respectively as hole selective contact. Unexpectedly, the FF and series resistance at MPP $\left(\mathrm{R}_{\mathrm{MPP}}\right)$ of the two cells are on the same level. We present an in-depth analysis of the two solar cells which reveals that lateral current transport is partly taking place also in the wafer at MPP. Furthermore, our analysis illustrates that the lower junctionrelated $\mathrm{R}_{\mathrm{S}}$ of $\mathrm{nc}-\mathrm{Si}(\mathrm{p})$ is hidden by a higher sheet resistance of the front-side ITO, albeit it was deposited with the same process.

\section{RESULTS}

\section{A. JV parameters \& EQE}

TABLE 1 shows the JV parameters of two SHJ solar cells with either a-Si(p) or nc-Si(p) as hole collecting layer of SHJ solar cells based on $2 \Omega \mathrm{cm}$ n-type FZ wafers, featuring a screenprinted front grid. The JV-curves shown in Fig. 1a are in-house measurements, to show the different behavior in high-forward bias. For the original certified JV-characteristics, please refer to Section II G of this paper. The JV parameters are on a similar level for both solar cells, as can be seen in TABLE 1. As can be seen from Fig. $1 b$ the slightly higher $\mathrm{J}_{\mathrm{SC}}$ for $\mathrm{nc}-\mathrm{Si}(\mathrm{p})$ stems from
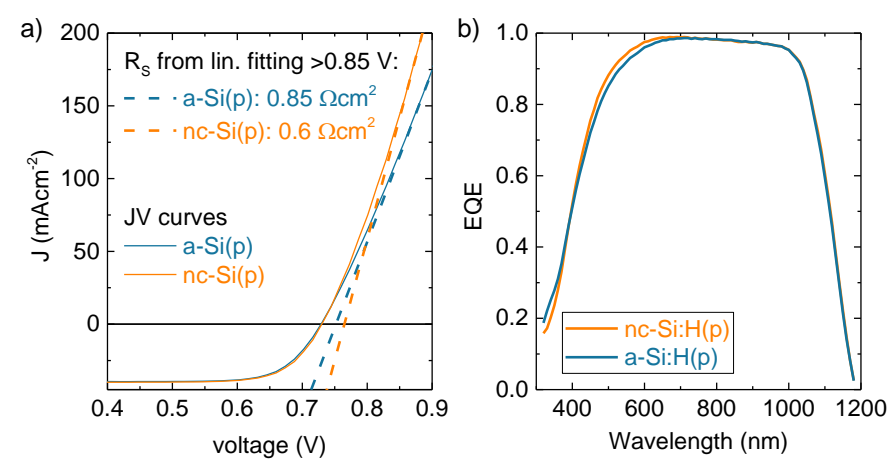

Fig. 1. a) JV curves, and b) EQE spectra of the two solar cells.

TABLE 1:

OVERVIEW OF JV PARAMETERS (OF CERTIFIED MEASUREMENT BY ISFH) OF THE TWO INVESTIGATED SHJ SOLAR CELLS. THE CELL FABRICATION PROCESS WAS IDENTICAL BUT FOR THE USE OF TWO DIFFERENT HOLE-SELECTIVE CONTACT MATERIALS. THEY BOTH FEATURE A SCREEN PRINTED FRONT GRID, AND SINGLE LAYER ARC (ITO). A BREAKDOWN OF THE SERIES RESISTANCE (IN HOUSE) IS ALSO SHOWN.

\begin{tabular}{|c|c|c|c|c|c|c|c|c|c|c|c|}
\hline $\begin{array}{l}\mathrm{A}_{\mathrm{da}}=4.029 \mathrm{~cm}^{2} \\
\text { ISFH certif. }\end{array}$ & $\begin{array}{l}\mathrm{V}_{\mathrm{OC}} \\
(\mathrm{mV})\end{array}$ & $\begin{array}{l}\text { FF } \\
(\%)\end{array}$ & $\begin{array}{l}\mathrm{J}_{\mathrm{SC}} \\
\left(\mathrm{mAcm}^{-2}\right)\end{array}$ & $\begin{array}{l}\eta \\
(\%)\end{array}$ & $\begin{array}{l}\mathrm{pFF} \\
(\%)\end{array}$ & $\begin{array}{l}\mathrm{R}_{\mathrm{MPP}} \\
(\mathrm{SunsVoc}) \\
\left(\Omega \mathrm{cm}^{2}\right)\end{array}$ & $\begin{array}{l}+0.85 \mathrm{~V} \\
\text { slope } \\
\left(\Omega \mathrm{cm}^{2}\right)\end{array}$ & $\begin{array}{l}\mathrm{R}_{\mathrm{TCO}, \text { lat }} \\
\text { (from } \mathrm{R}_{\square} \text { ) } \\
\left(\Omega \mathrm{cm}^{2}\right)\end{array}$ & $\begin{array}{l}\text { calc } \mathrm{R}_{\mathrm{S} \text {,lat }} \\
\text { @MPP } \\
\left(\Omega \mathrm{cm}^{2}\right)\end{array}$ & $\begin{array}{l}\mathrm{R}_{\mathrm{S} \text {,finger }} \\
\left(\Omega \mathrm{cm}^{2}\right)\end{array}$ & $\begin{array}{l}R_{\text {S,residual }} \\
\left(\Omega \mathrm{cm}^{2}\right)\end{array}$ \\
\hline $\mathrm{a}-\mathrm{Si}(\mathrm{p})$ & 731.9 & 81.11 & 39.14 & 23.23 & 85.6 & 0.93 & 0.85 & 0.42 & 0.30 & 0.13 & 0.50 \\
\hline nc-Si(p) & 734.1 & 81.07 & 39.41 & 23.45 & 85.7 & 0.89 & $0.60<$ & 0.72 & 0.38 & 0.13 & 0.38 \\
\hline
\end{tabular}


reduced parasitic absorption mainly in the visible (400-700 $\mathrm{nm}$ ), but also (less visible on the graph) in the IR (1000$1150 \mathrm{~nm}$ ) wavelength range. The latter is most probably due to lower FCA in the case of nc-Si(p) resulting from the lower amount of charge carriers in the ITO as discussed below.

\section{B. FF loss analysis}

As seen from Fig. 1a, the JV curves of the two cells are nearly identical in the fourth quadrant. Also the pseudo FF (pFF) obtained via SunsVoc is nearly identical for both solar cells, as
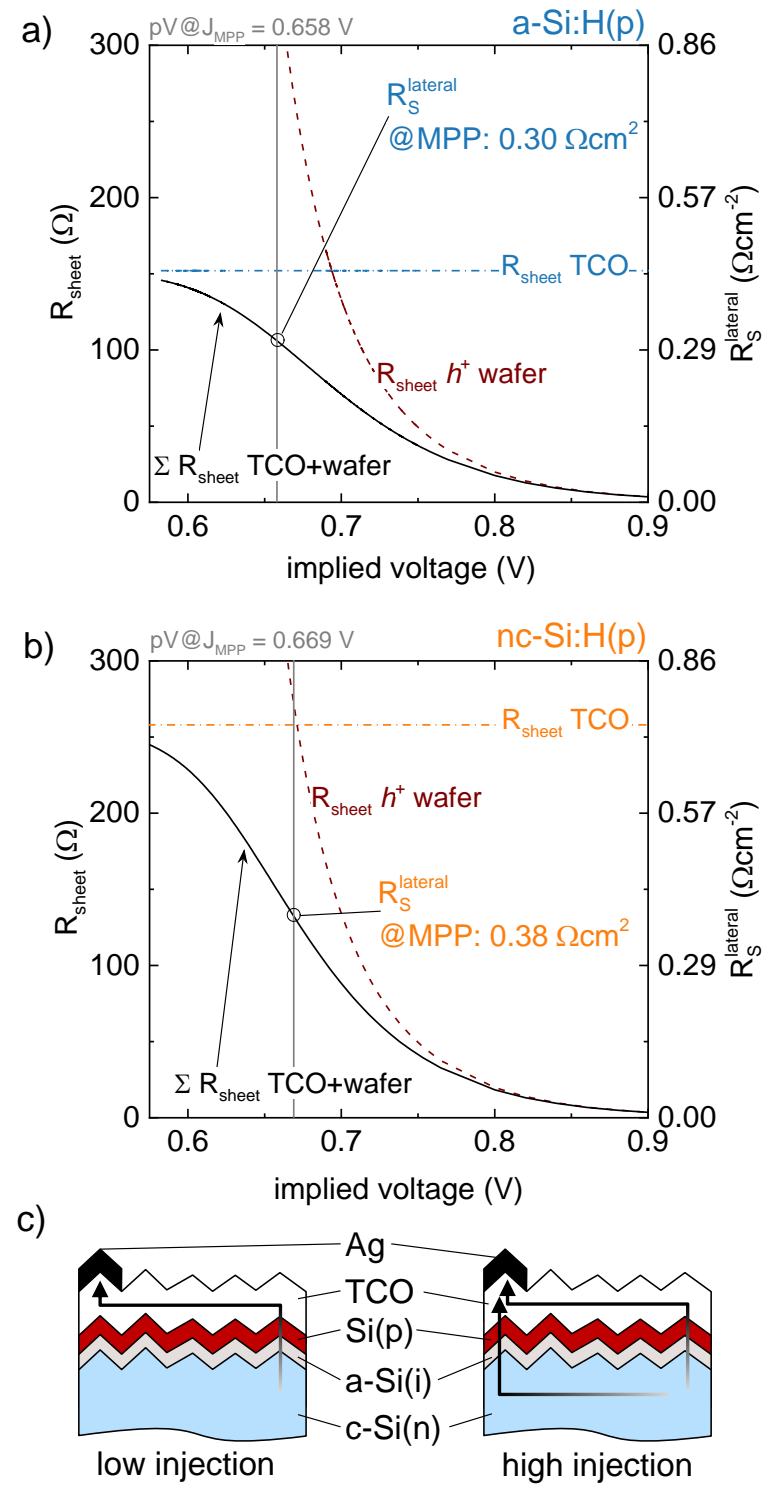

Fig. 2. Bias-voltage-dependent composition of the lateral sheet resistance for a) the a-Si(p) SHJ cell and b) the nc-Si(p) cell. The sheet resistance for holes in the n-type wafer is strongly bias-voltage dependant. On the right y-axis, the sheet resistance is expressed as the series resistance in the cell for the solar cell front grid dimensions. Schematic current flow for low- and high-injection conditions are depicted in c). shown in TABLE 1. The series resistance at maximum power point $\left(\mathrm{R}_{\mathrm{MPP}}\right.$, calculated from the comparison of the pseudo-JV and the light-JV at MPP) are similar for both solar cells as well. However, in high forward bias conditions (e.g. at $+0.85 \mathrm{~V}$ ), the curves differ significantly. Such behavior could be attributed to a non-linear $\mathrm{R}_{\mathrm{S}}$, as often present in SHJ devices. Yet, nc-Si is expected to lower the contact resistance at the $\mathrm{Si} / \mathrm{ITO}$ interface versus a-Si [4], [5] and to reduce non-linearity of the series resistance.

\section{Lateral current flow in high injection}

ITO sheet resistances measured directly on the wafers were $\mathrm{R}_{\square, \mathrm{ITO}}{ }^{\mathrm{ncSi}(\mathrm{p})}=258 \Omega$ for the $\mathrm{nc}-\mathrm{Si}(\mathrm{p})$, and $\mathrm{R}_{\square, \mathrm{ITO}}{ }^{\mathrm{aSi}(\mathrm{p})}=152 \Omega$ for the a-Si(p), despite identical deposition conditions. We attribute this to the lower hydrogen content in $n c-S i(p)$ over a-Si(p), leading to a lower hydrogenation of the ITO [3]. In high forward bias, the n-type wafer is in high-injection, thus there is a high density of holes contributing to the wafer's conductivity. Therefore, a lateral hole current in the wafer can help to reduce the lateral resistance towards the grid fingers. We calculated the sheet resistance for holes based on the injection-dependent excess charge carrier density taken from lifetime measurements. Fig. $2 b$ shows that at MPP for the nc-Si(p) device, lateral hole conductance in the wafer is at a similar level as the lateral conductance provided by the ITO. For the a-Si(p) device, lateral hole conductance in the wafer at $\mathrm{J}_{\mathrm{MPP}}$ is slightly lower, mainly due to a lower injection/implied voltage at $\mathrm{J}_{\mathrm{MPP}}$. Proportionally, lateral conductance in the wafer is higher for nc-Si(p) due to the higher $\mathrm{R}_{\square, \mathrm{ITO}}{ }^{\mathrm{ncSi}(\mathrm{p})}$ over $\mathrm{R}_{\square, \mathrm{ITO}}{ }^{\text {aSi }}(\mathrm{p})$. As a first order estimate, we assume zero contact resistance between the two layers (TCO and wafer), which allows for the simple calculation of the effective $R_{\square}\left(R_{\square, T C O} \| R_{\square \text {,wafer }}\right)$. Thus, the resistance due to lateral transport in the device amounts to $0.30 \Omega \mathrm{cm}^{2}$ for a-Si(p) and $0.38 \Omega \mathrm{cm}^{2}$ for $\mathrm{nc}-\mathrm{Si}(\mathrm{p})$ according to our simplified calculations. The finger resistance $R_{\text {finger }}$ is the same for both solar cells and amounts to $0.13 \Omega \mathrm{cm}^{2}$. Subtracting these values from $\mathrm{R}_{\mathrm{MPP}}$ of the two devices leads to a residual $R_{S}$ of $0.50 \Omega \mathrm{cm}^{2}$ for a-Si(p) and $0.38 \Omega \mathrm{cm}^{2}$ for nc-Si(p). Assuming other resistance contributions to be identical for the two devices (vertical resistance, contact resistance $\mathrm{i} / \mathrm{n} / \mathrm{ITO}$, and ITO/finger), we attribute the lower $\mathrm{R}_{\mathrm{S} \text {,residual }}$ for $\mathrm{nc}-\mathrm{Si}(\mathrm{p})$ to a lower contact resistance $\mathrm{i} / \mathrm{p} / \mathrm{ITO}$. This can also be seen in the first quadrant, but is not obvious when analysing the JV curve only in the fourth quadrant.

\section{Numerical Simulations}

To further examine the observed phenomena of lateral transport, numerical device simulations were performed using Sentaurus TCAD. A unit cell with the same dimensions as the two experimental solar cells was defined and the JV parameters were calculated for different $\mathrm{R}_{\text {sheet }}$ of the front TCO. To account for additional $\mathrm{R}_{\mathrm{S}}$ such as grid-finger, busbar, and contact resistances, an additional lumped $R_{S}$ of $0.5 \Omega \mathrm{cm}^{2}$ was included 


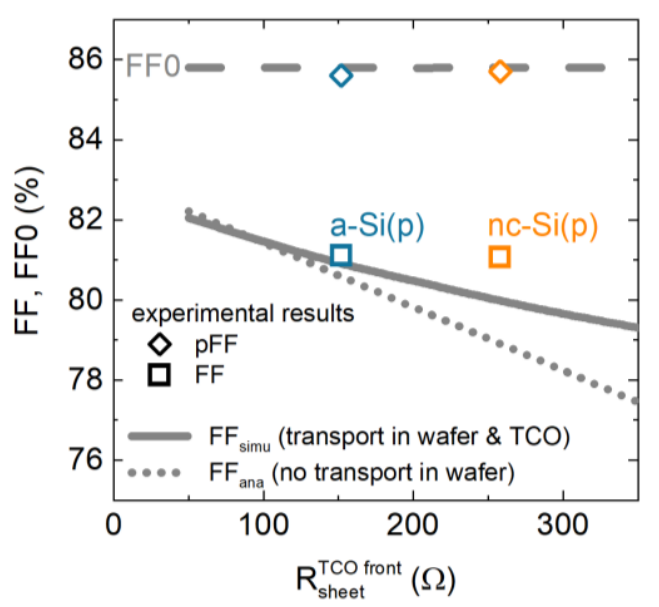

Fig. 3. Solid line numerical device simulation, dashed line: FF0 derived from numerical simulations as described by Bowden et al., dotted line: calculated from the simulated FF0, Rsheet ${ }^{\mathrm{TCO}}$ front and an additional lumped $\mathrm{R}_{\mathrm{S}}$ of $0.5 \Omega \mathrm{cm}^{2}$. Scatter: experimental FF and FF0 of the two experimental SHJ solar cells.

in the simulation. The FF of the simulations is shown in Fig. 3 $\left(\mathrm{FF}_{\text {simu }}\right)$. The $\mathrm{FF} 0$ of the simulation was obtained with the method of Bowden et al. [6] from the additional simulation of a JV curve at 0.05 suns. From this FF0, the $\mathrm{R}_{\text {sheet }}{ }^{\text {front ITO }}$ and an additional lumped $\mathrm{R}_{\mathrm{S}}$ of $0.5 \Omega \mathrm{cm}^{2} \mathrm{FF}_{\text {ana }}$ was calculated with the analytical equation of Green et al. (eq. 7 in [7]). Thus, $\mathrm{FF}_{\text {simu }}$ takes into account also lateral hole transport in the silicon wafer, while $\mathrm{FF}_{\text {ana }}$ does not. $\mathrm{FF}_{\text {simu }}$ is higher than $\mathrm{FF}_{\text {ana }}$, especially for higher $\mathbf{R}_{\text {sheet }}{ }^{\text {TOC front }}$. This confirms that there is an additional transport path in the wafer, which is not considered when calculating the lateral resistance with the analytical equation and considering only $\mathrm{R}_{\text {sheet }}{ }^{\mathrm{TOC}}$ front. The FF of the experimental $\mathrm{SHJ}$ device with a-Si(p) hole contact is close to the simulated FF, indicating that with the simulation and the additional $0.5 \Omega \mathrm{cm}^{2}$ of lumped $\mathrm{R}_{\mathrm{S}}$, the a-Si(p) device is better described by the simulation than the device with nc-Si(p) hole contact. As busbar and finger resistances are the same for both devices, the higher FF of the nc-Si(p) device versus the simulation underlines that the contact resistance $\mathrm{i} / \mathrm{p} / \mathrm{ITO}$ of the $\mathrm{nc}-\mathrm{Si}(\mathrm{p})$ devices lower than of the a-Si(p) device.

\section{E. Low-temperature transport}

Temperature dependent JV parameter of the two solar cells are shown in Fig. 5. With nc-Si(p), the linear increase of $\mathrm{V}_{\mathrm{OC}}$ with decreasing temperature is maintained to lower temperatures compared with a-Si(p). This is due to dopant freeze-out happening at lower temperature, as shown earlier [8] [4]. For both solar cells, the FF drops with decreasing temperature. For a-Si(p) this happens at higher temperature $\left(30^{\circ} \mathrm{C}\right)$ compared with nc-Si $(\mathrm{p})\left(0^{\circ} \mathrm{C}\right)$. We attribute this to the higher activation energy in a-Si(p) compared with nc-Si(p), impacting carrier transport in two ways: via (temperaturedependent) bulk conductivity in the hole selective layer and in a-Si(i), and temperature-enhanced current transport at the $\mathrm{p} / \mathrm{ITO}$ and $\mathrm{a}-\mathrm{Si} / \mathrm{c}-\mathrm{Si}$ interface. The temperature-dependent JV

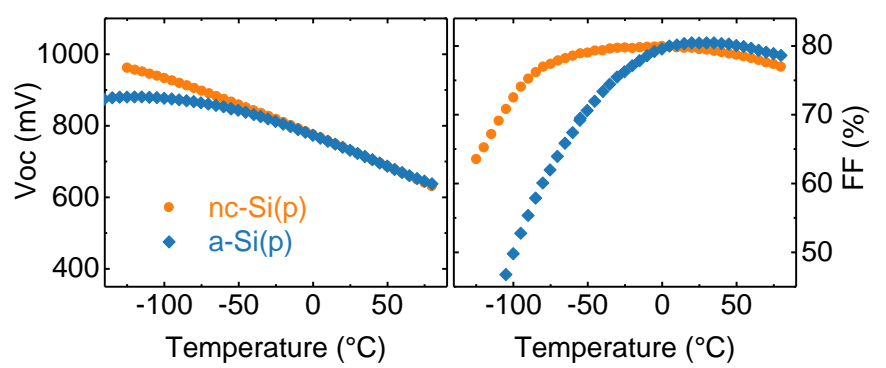

Fig. 5. Temperature-dependent $\mathrm{V}_{\mathrm{OC}}$ and FF the two solar cells. The nc-Si $(\mathrm{p})$ enables higher $\mathrm{V}_{\mathrm{OC}}$ at $-100^{\circ} \mathrm{C}$, indicating that dopant freeze-out is happening later due to the lower activation energy of nc-Si(p). The slightly lower FF for temperatures $>5{ }^{\circ} \mathrm{C}$ of nc-Si(p) compared with a-Si(p) is probably due to a contacting issue during the measurement.

measurements are equally revealing the superior properties as hole-selective-contact of nc-Si(p) over a-Si(p), currently hidden by the increased resistivity of the ITO.

\section{F. ITO sheet resistance on different substrates}

ITO properties can change depending on the layer that the ITO is deposited onto [3]. Upon annealing, if hydrogen is present in the substrate, it can diffuse into the ITO and change its properties [9]. Fig. 4 shows the sheet resistance on bare glass as well as on glass coated with either a-Si(p) or nc-Si(p), and for ITOs deposited with different $\mathrm{O} 2$ flows during PVD. For an $\mathrm{O} 2$ flow of $1 \%$ in Ar during sputtering, there is no influence of the substrate. With higher $\mathrm{O} 2$ flow (i.e. lower charge carrier density in the ITO), hydrogenation from the substrate becomes increasingly important (note the $y$-axis break). Hydrogenation is more pronounced for a- $\mathrm{Si}(\mathrm{p})$ as lower $\mathrm{R}_{\text {sheet }}$ is obtained vs the ITO on nc-Si(p) and even much lower $\mathrm{R}_{\text {sheet }}$ vs ITO on bare glass, where no hydrogenation is happening. Also shown in Fig. 4, are three series resistance values caused by TCO with a certain $\mathrm{R}_{\text {sheet }}$ when used as front TCO in SHJ cells with our grid design.

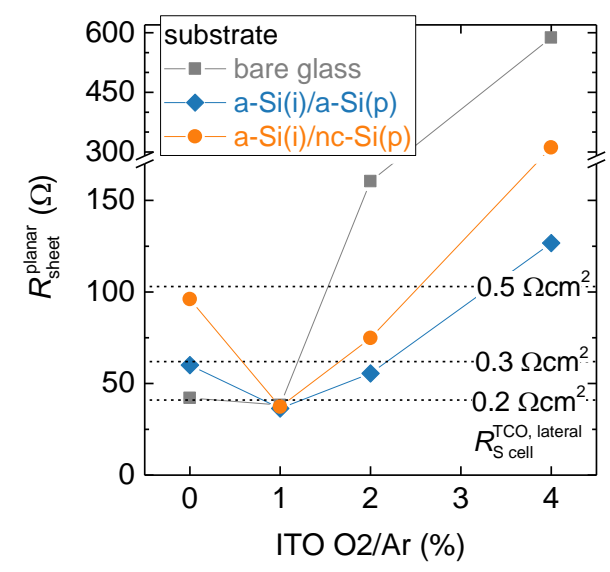

Fig. 4. R $\mathrm{R}_{\text {sheet }}$ on planar glass substrates, coated with different SHJ layer stacks, deposited via PECVD. The dashed line indicate the $\mathrm{R}_{\mathrm{S}}$ caused when a TCO with this $\mathrm{R}_{\text {sheet }}$ would be used as front TCO in our standard SHJ cells. 


\section{G. Certified JV curves}

In Fig. 6 we show the plots of the certified JV-characteristics as provided by ISFH CalTec, for reference.

a)

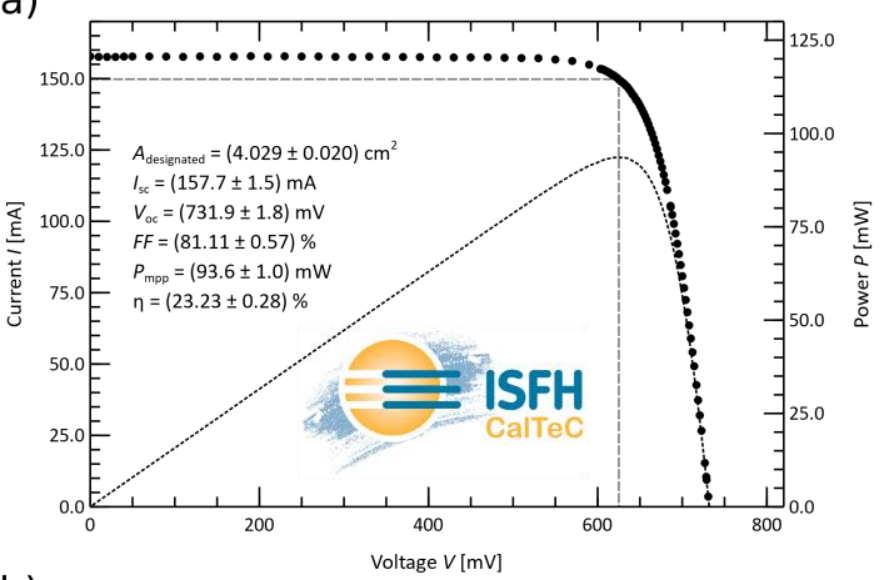

b)

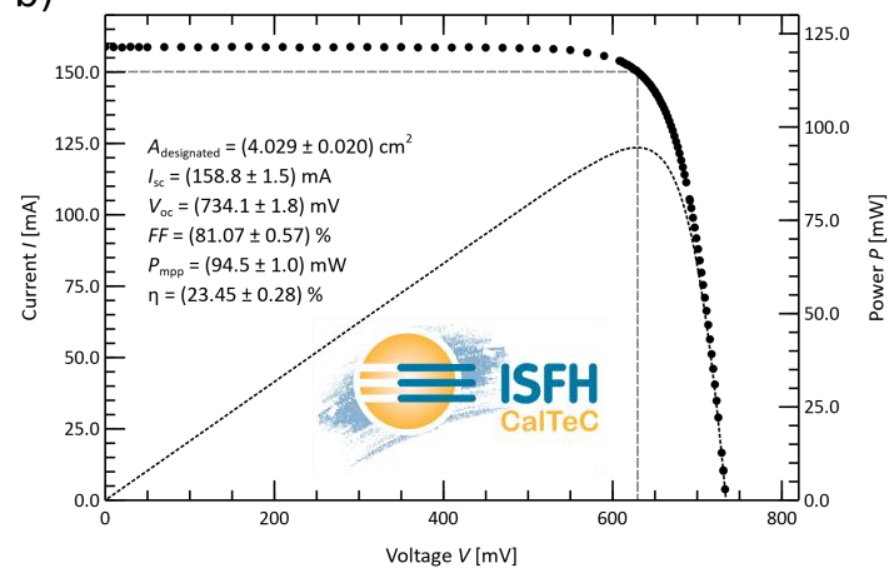

Fig. 6. Certified JV-characteristics of the SHJ solar cell with a) $\mathrm{a}-\mathrm{Si}(\mathrm{p})$ and $\mathrm{b}) \mathrm{nc}-\mathrm{Si}(\mathrm{p})$ hole-selective contact layer.

\section{SUMMARY}

We showed that lateral current transport in the wafer is relevant also for front-junction SHJ solar cells. The impact of the sheet resistance of the TCO is reduced when the wafer is in high-injection conditions. This phenomenon has to be considered for thorough loss analysis in order to discriminate between different loss pathways.

We furthermore confirmed that $n c-S i(p)$ can reduce the contact resistance of the i/p/ITO stack in SHJ solar cells and that it is thus a promising hole selective layer for SHJ front junction cells, as also short circuit current in the blue wavelength range is increased. ITO sheet resistance is higher on $n c-S i(p)$ compared with a-Si(p) which shows that accompanying TCO adaptation is necessary when optimizing SHJ contact layers.

\section{REFERENCES}

[1] M. A. Green et al., "Solar cell efficiency tables (Version 53)," Prog. Photovoltaics Res. Appl., vol. 27, no. 1, pp. 312, Jan. 2019.

[2] J. Haschke, O. Dupré, M. Boccard, and C. Ballif, "Silicon heterojunction solar cells: Recent technological development and practical aspects - from lab to industry," Sol. Energy Mater. Sol. Cells, vol. 187, no. July, pp. 140153, Dec. 2018.

[3] K.-U. Ritzau, T. Behrendt, D. Palaferri, M. Bivour, and M. Hermle, "Hydrogen doping of Indium Tin Oxide due to thermal treatment of hetero-junction solar cells," Thin Solid Films, vol. 599, pp. 161-165, Jan. 2016.

[4] G. Nogay et al., "Nanocrystalline Silicon Carrier Collectors for Silicon Heterojunction Solar Cells and Impact on LowTemperature Device Characteristics," IEEE J. Photovoltaics, vol. 6, no. 6, pp. 1654-1662, 2016.

[5] A. B. Morales-Vilches, L. Mazzarella, M. Hendrichs, L. Korte, R. Schlatmann, and B. Stannowski, "Nanocrystalline vs. amorphous n-type silicon front surface field layers in silicon heterojunction solar cells: Role of thickness and oxygen content," in 33rd European Photovoltaic Solar Energy Conference and Exhibition, 2017, pp. 715-719.

[6] S. Bowden and A. Rohatgi, "Rapid and accurate determination of series resistance and fill factor losses in industrial silicon solar cells," 17th Eur. Photovolt. Sol. Energy Conf., 2001.

[7] M. A. Green, "Accuracy of analytical expressions for solar cell fill factors," Sol. Cells, vol. 7, no. 3, pp. 337-340, Dec. 1982.

[8] M. Mikolášek, J. Racko, and L. Harmatha, "Analysis of low temperature output parameters for investigation of silicon heterojunction solar cells," Appl. Surf. Sci., vol. 395, pp. 166-171, 2017.

[9] J. Haschke et al., "Annealing of silicon heterojunction solar cells: Interplay of solar cell and Indium-Tin-Oxide properties," IEEE J-PV, doi: 10.1109/JPHOTOV.2019.2924389, 2019. 